\title{
Küreselleşme ve İktisadi Entegrasyon Bağlamında 2000 Sonrasında Türkiye Ekonomisi
}

\author{
Yunus Kaya*
}

\begin{abstract}
Öz: Bu çalışmada, 1980 sonrasında Türkiye'nin küresel ekonomiye entegrasyonu ve bunun sonuçları incelenmiştir. Tarihçesi, içeriği ve etkileri konusunda sosyal bilimlerde önemli fikir ayrılıkları olsa da, küreselleşme son otuz yılda Türkiye'nin ekonomisini, toplusal dokusunu ve devlet yapısını dönüştüren bir güç olarak ortaya çıkmıştır. 1980 yılında ekonomisi içe dönük ve büyük oranda devletin denetiminde olan Türkiye, 2010 yılına gelindiğinde dış ticarete dayalı, ihracata yönelik küçük ve orta büyüklükte işletmelerin rolünün büyük oranda arttığı, devletin doğrudan varlığının asgari düzeye indiği bir yapıya geçmiştir. Bu dönüşümün Türkiye'deki çalışma hayatına ve toplumsal yapıya büyük bir etkisi olmuştur. Türkiye, çalışan nüfusunun yarısından fazlasının tarımda istihdam edildiği bir yapıdan, hizmet sektörü ve sanayinin en büyük işverenler hâline geldiği bir yapıya evrilmiştir. Fakat tüm bu değişimlere rağmen küreselleşme süreci içinde büyüyen ve dönüşen ekonomi, toplumun geneline yayılan bir refah oluşturamamıştır. Yaşanan ekonomik büyümeye, ithalat ve ihracattaki patlamaya ve hatırı sayılır dış sermaye girişine rağmen fakirlik, işsizlik ve gelir adaletsizliği konularında önemli bir iyileşme henüz sağlanamamıştır. Türkiye'de küreselleşme sürecinden en kazançlı çıkan kesim ise küresel ekonomiyle iş yapan veya küresel ekonomiyle bağlantıyı yürüten girişimci ve profesyonel sınıflar ve gruplar olmuştur. Bu dönemde, devlet bürokrasinin eskiden beri süregelen toplum ve ekonomi üzerindeki gücü de azalmıştır. Toplumsal yapı içinde bürokratlar saygınlık ve zenginlik açısından küreselleşme sürecinde katlanarak büyüyen girişimci ve profesyonel sınıflar tarafından gölgelenir hâle gelmiştir.
\end{abstract}

Anahtar Kelimeler: Türkiye, Küreselleşme, İş Gücü, Fakirlik, Eşitsizlik, Bürokrasi.

Abstract: This paper analyzes the process of globalization and its impact on labor, state, social inequality, and poverty in Turkey between 1980 and 2010. In 1980, Turkey had a small economy with limited industrialization, which was achieved mainly through import substitution industrialization policies. Since opening its doors to global economy, following the economic crises of the late 1970s, Turkish economy has grown rapidly, although it also suffered from frequent economic crises. In the process, Turkey has become a significant exporter of, mostly low-technology, but also increasingly medium and high technology, manufactured goods. This transformation had profound effects on the social structure of Turkey and the work life in the country. Turkey is no longer an agrarian society. In 2010, less than 25 percent of all working people were employed in agriculture compared to over 50 percent in 1980. However, after thirty years of globalization, liberalization and significant economic growth, poverty, social inequality and unemployment remain mostly unresolved. During these thirty years, Turkey experienced only modest decline in poverty while unemployment and social inequality remained high. Another significant change in Turkey during this period was the decline in the relative importance and power of the bureaucratic elite. The traditionally strong bureaucratic elite lost its direct role in the economy with the globalization of Turkish economy, which diminished its overall influence, while managerial and professional social classes expanded in size and increased their influence.

Keywords: Turkey, Globalization, Labor, Poverty, Inequality, Bureaucracy.

* Dr., University of North Carolina Wilmington.

Atıf(:) Kaya, Y. (2010). Küreselleşme ve Iktisadi Entegrasyon Bağlamında 2000 Sonrasında Türkiye Ekonomisi. Insan ve Toplum, 1 (1), 67-85. 


\section{Giriş}

Günümüz Türkiye'sinin iktisadi, sosyal ve kurumsal yapısını 24 Ocak Kararları ve 12 Eylül 1980 Darbesi ile başlayan iktisadi entegrasyon ve küreselleşme süreçlerini iyi tahlil etmeden anlamak mümkün değildir. Türkiye, 1980 yılından itibaren Batı'da Reagan ve Thatcher ile başlayan ve kısa sürede IMF ve Dünya Bankası gibi kurumlar aracılığıyla tüm dünyaya empoze edilen ekonomilerin libarelleştirilmesi ve devletlerin ekonomiden el çektirilmesi sürecine ilk katılan ve sürecin en hızlı geliştiği ülkelerden biri olmuştur. Bu açıdan Türkiye'nin küresel ekonomiye entegrasyonunun incelenmesi kendi başına önemli bir konu olsa da sürece daha sonraki yıllarda veya aşamalı olarak katılan ülkeleri ne gibi değişimler ve toplumsal sonuçlar beklediğinin anlaşılması açısından da oldukça önemlidir. Küresel ekonomiye entegrasyon sürecinde Türkiye'de devlet ve kurumsal yapı, çalışma hayatı ve toplumsal doku çok önemli değişikliklere uğramıştır.

Bu çalışmada Türkiye'nin küreselleşme ve küresel iktisadi entegrasyon macerasının ve sonuçlarının kısa bir tartışmasını yapacağız. Önce sosyal bilimler ve entellektüel çevrelerde küreselleşme sürecinin nedenleri, tarihçesi ve gelişimi konularındaki giderek genişleyen ve hâkim olunması güçleşen tartışmalara değinip daha sonra Türkiye'nin küresel ekonomik entegrasyonunu bu çerçevede anlamlandırmaya çalışacağız. Daha sonra ise küresel iktisadi entegrasyonun Türkiye'nin devlet ve kurumsal yapısına, çalışma hayatına ve toplumsal refaha olan etkilerini ayrı ayrı tartışacağız.

Bu saydığımız konularda yapılan yaygın çalışmalar ve çalışmada yapacağımız analizler göstermiştir ki Türkiye, 1980'den beri geçen otuz yılda ithal ikameci ve devletçi ekonomi anlayışından uluslararası ticarete dayanan bir piyasa ekonomisine geçmiş; 1980'de sanayisi iç piyasa için üretim yapan, tarım ürünleri ve ham madde satıp teknoloji satın alan Türkiye süreç içinde düşük ve orta seviye teknoloji gerektiren ürünleri üreten ve özellikle coğrafi olarak yakın olduğu Avrupa Birliği ülkeleri için ucuz iş gücü ve mamul sağlayan bir ülke hâline gelmiştir. Süreç içinde küresel ekonomiye iş yapan girişimciler ve küresel ekonomiyle bağlantıyı sağlayan profesyoneller zenginleşirken, bürokrasi ve küresel ekonomiye uyum sağlayamayan sermaye gerilemiştir. Ayrıca özellikle şehirlerde tarımdan ve kırdan kopup gelerek küresel ekonomi için üretim yapan girişimcilere ucuz iş gücü sağlayan vasıfsız işçi kütleleri oluşmuştur. Bunun sonucu olarak toplumsal yapıda kutuplaşma artmış, en tepede görece küçük girişimci ve profesyonel sınıf zenginleşirken toplumun diğer kesimlerinin durumlarında pek bir iyileşme yaşanmamıştır (Kaya, 2008). Son otuz yıl boyunca, işsizlik oranı hep yüksek kalmış, gelir adaletsizliği ve fakirlik gibi konularada yeterince bir iyileşme sağlanamamıştır.

Bu konulara ayrıntılı olarak değinmeden önce küreselleşme sürecinin ne olduğu ve tarihsel bağlamda nasıl anlaşılması gerektiği konusundaki tartışmalara değinmek yerinde olacaktır. Takip eden bölüm, dünyadaki küreselleşme sürecinin ve bu süreci anlamlandırmak için yapılan çalışmaların kısa bir analizini içermektedir. 


\section{Küreselleşme Tanımı ve Küreselleşme Teorileri}

Küreselleşme genel olarak son 30-35 yılda ulusal ekonomilerin ve toplumların giderek artan ve hızlanan entegrasyonunu adlandırmak için ortaya çıkmış bir kavramdır. Fakat, Guillen (2001), O'Riain (2000), Gereffi (2005), Brady, Beckfield ve Zhao (2007) tarafından yapılan geniş literatür taramalarının da gösterdiği gibi sosyal bilimlerde ve entellektüel çevrelerde küreselleşmenin tanımı, tarihçesi, içeriği ve etkileri hakkında çok büyük fikir ayrılıkları mevcuttur. Tarihçesi bazı sosyal bilimciler tarafından çok eskilere dayandııısa da, bugün anlaşıldığı şekliyle küreselleşme son 15-20 yıl içinde ortaya çıkmış bir kavramdır. 1990'ların başında bir elin parmakları sayısınca olan küreselleşme çalışmaları (Robertson, 1992), 2000'lerden sonra takip edilmesi ve hâkim olunması imkânsız bir genişliğe kavuşmuştur. Küreselleşme üzerine yapılan sayısız çalışma ve şiddeti giderek artan tartışmaların karmaşıklığı, küreselleşmenin kapsamını ve temel dinamiklerini tanımlamayı zorlaştırmaktdır.

Sosyal bilimlerde küreselleşme hakkındaki en temel tartışmalardan biri bugün tecrübe ettiğimiz ve küreselleşme olarak adlandırdığımız bu sürecin yeniliği hakkındadır. Küreselleşme fikrine şüpheyle yaklaşan bazı akademisyenler (örneğin Bairoch, 1996; Hirst ve Thompson, 1996), şu an yaşadığımız sürecin geçmişteki bazı dönemlere, özellikle on dokuzuncu yüzyılın sonlarına çok benzediğini ve yeni bir şey taşımadığını iddia etmişler ve küreselleşme olgusunu tümden reddetmişlerdir. Hatta daha da ileri giderek on dokuzuncu yüzyılın sonunda dünya ekonomisinin bugünden daha entegre ve daha küresel olduğunu iddia etmişlerdir (Obstfeld ve Taylor, 2003). Bu araştırmacılar, ondokuzuncu yüzyılın ikinci yarısında görülen buharlı gemilerin ve telgrafın icadı gibi etmenlere bağlı olarak dünyanın ondan önceki zamanlarda görülmeyen ve günümüze benzeyen bir biçimde entegre olduğunu, dış ticaretin ve uluslararası yatırımların ancak son yıllarda ulaşılabilen seviyelere ulaştığını belirtmişlerdir (Hirst ve Thompson, 1996). Onlara göre o zamanlar İngiliz hegemonyası altında işleyen dünya ekonomisi, bugün Amerikan hegemonyası altında işlemektedir ve o günlerden bugüne çok birşey değişmemiştir.

Bu yaklaşımın tam zıddı olarak ise özellikle iş dünyası kaynaklı, küreselleşmenin, komünist blokun çöküşü sonrasında daha önceleri benzeri görülmemiş bir dünya yarattığını iddia eden yaklaşımlar da ortaya çıkmıştır. Mesela, 1990'ların sonunda "iş gurusu" olarak da bilinen Japon Kenichi Ohmae $(1995,1999)$, ulusal devletlerin etkisinin ortadan kalktığı ve çok uluslu şirketler tarafından yönetilen bir dünyanın oluşmaya başladığını, hayatta kalmak isteyen her şirketin çok uluslu bir yapıya kavuşması gerektiğini iddia etmiştir. Benzer bir etikete sahip olan Greider (1997: 24) de "Bugün artık sermayenin kanatları var. Sermaye yirmi iş gücü piyasası ile birden bağlantılı olup aralarından istediğini seçebilir." demiştir. Yine benzer bir biçimde, New York Times yazarı Friedman $(1999,2006)$ Amerikan ve dünya kamuoyunda yaygın biçimde okunan kitaplarında küreselleşmenin mesafeleri ortadan kaldırıp tek hatta düz bir dünya oluştur- 
duğunu iddia etmiştir. Tabii, bu yaklaşımlar iş dünyasında ve genel halk nezdinde çok tutulmuşsa da akademik çevrelerde pek itibar görmemiştir.

Küreselleşme teorilerinin ayrı bir eleştirisi de dünya sistemi ve bağımlılık okullarından gelmiştir. Bu yaklaşımlar temel olarak merkez ülkeler olarak adlandırdıkları sanayileşmiş ülkelerin kendileri dışındaki ülkeleri (çevre ülkeler) sömürüye tabi tuttukları bir dünya sisteminin, Batı'da sanayileşmenin ve yayılmacılığın başladığı on altıncı ve on yedinci yüzyıldan beri süregeldiğini iddia etmişlerdir (Wallerstein, 1974, 1980, 1989). Bu bağlamda, küreselleşmeyi dünya sisteminin yeni bir şekli veya safhası olarak görmektedirler. Dünya sistemi okulunun kurucusu Wallerstein (2000), küreselleşme terimini dünyadaki güncel durumun yanlış okunması olarak nitelemiştir. Ona göre küreselleşme kendiliğinden meydana gelen doğal bir süreç değil, dünya sistemine hâkim olan güçler tarafından empoze edilen bir projedir ve küreselleşme olarak adlandıran süreç dünya sisteminin yeni bir döngüye girmesinden başka birşey değildir. Bu iddiayı desteklemek için yaptıkları çalışmada, yine dünya sistemi okuluna mensup olan ChaseDunn, Kawano ve Brewer (2000), uluslararası ticaretin döngüler hâlinde ilerlediğini ve 1970 sonrasında bir niteliksel kopma yaşanmadığını iddia etmişlerdir. Benzer biçimde, McMichael $(2000,2001)$ küreselleşmeyi İkinci Dünya Savaşı sonrası öne çıkarılan kalkınma projesinin yerinie alan bir proje olarak nitelendirmiştir.

Küreselleşmeyi tamamen reddeden veya çok abartan bu yaklaşımlara karşı belli başlı küreselleşme teorisyenleri (örneğin Held, McGrew, Goldblatt ve Perraton, 1999; Robertson, 1992; Theborn, 2000), küreselleşmenin kökenlerinin son yirmi yıldan çok daha eskilere gittiğini kabul etmekle birlikte, yaşadığımız dönemin ayırt edici özelliklerine dikkat çekmişlerdir. Baldwin ve Martin (1999) yirminci yüzyılın ikinci çeyreğinde ulaşım ve iletişim teknolojilerinde yaşanan gelişmelere dikkat çekerlerken, Dicken (2003) önceki dönemlerin yüzeysel entegrasyonunun bugün fonksiyonel bir entegrasyonla yer değiştirdiğini söylemiştir. Bu araştırmacılara göre bugünkü uluslararası ticaret ve dış yatırımlar dünya ekonomisinin büyüklüğüne ve ülke gayrisafi millî hasılalarına oranları açısından on dokucuncu yüzyılın ikinci yarısına benzerlik gösterse de, iki dönem nakliyat ve iletişim teknolojilerinin hızı ve maliyetlerinin düşüklüğü, ticaret ve yatırımlarda önemli rol oynayan ülkelerin sayısının çokluğu ve çeşitliliği açısından birbirinden ayrılmaktadır (Baldwin ve Martin, 1999). Ayrıca, finans sektöründeki yatırım araçlarının çokluğunun, yatırımcıların dünyanın her yerinde gerçek zamanlı yatıım yapma kabiliyetinin ve yatırımların yaygınlığının ancak bugün ortaya çıkmış bir durum olduğunu belirtmişlerdir (Held vd., 1999). Bu çalışmada benimsenen teorik çerçeve de bu anlayışı takip etmekte ve geçmişten gelen devamlılıkları kabul etmekle beraber, 1970 'ler ve 1980 'ler sonrası oluşan yeni durumlara vurgu yapmaktadır.

Günümüzde tecrübe ettiğimiz hâliyle küreselleşmenin ekonomik alandaki en önemli farklılıklarından biri meta üretiminin eski Fordist, bütüncül üretim yapılarından parçalanmış ve dünya üzerine dağılmış bir yapıya geçişidir. Bu yeni yapılanma birçok- 
ları tarafından "yeni uluslararası iş bölümü" olarak da adlandırılmıştır (Castells, 1996; Fröbel, Heinrichs ve Kreye, 1980; Hoogvelt, 1997). 1970'lerde başlayan bu sürecin 1980'lerin başından itibaren büyük bir ivme ve yepyeni bir karakter kazandığını görmekteyiz. 1970'ler boyunca petrol krizi, merkez ülkelerde yükselen işçi maliyetleri ve siyasal problemlerle krize giren dünya ekonomik sistemi 1970'lerin ortalarından itibaren önemli yapısal değişikliklere uğradı. Dünya sistemi ve bağımlılık okullarınca ayrıntılı bir biçimde resmedilmiş olan, merkez (sanayileşmiş) ülkelerin çevre ve yarı çevre (gelişmekte olan) ülkelerden gelen ham maddeyi ürüne çevirerek diğer merkez ülkelere ve çevre ülkelere sattığı ekonomik sistem yerini üretimin parçalandığı ve tüm dünyaya yayıldığı bir sisteme bırakmaya başladı.

Bu yeni sistemde üretim, sanayileşmiş ülkelerden gelişmekte olan ülkelere kaymaya başlamıştır. 1970'lerden itibaren gelişmiş ülkelerdeki birçok firma artan işçi maliyetleri, yüksek vergiler ve çevre kirliliği düzenlemelerinden kurtulmak ve kârılıklarını artırmak amacıyla özellikle emek yoğun sektörlerdeki üretim faaliyetlerini gelişmekte olan ülkelere taşımışlardır. Kendi ülkelerinde ise sadece yönetim, pazarlama, araştırma ve geliştirme ve tasarım gibi stratejik ve yüksek nitelikte iş gücü gerektiren faaliyetleri bırakmışlardır. Bu süreçte, taşıma ve iletişim teknolojilerindeki gelişmeler önemli ölçüde etkili olmuştur. Özellikle bilgisayar, fak, telex ve daha sonraları internet gibi araçlar değişik bölgelere yayılan üretim faaliyetlerinin koordinasyon ve takibini mümkün kılmıştır. Üretim gelişmekte olan ülkelere iki yolla transfer edilmiştir. Bunlardan birincisi gelişmekte olan ülkelere doğrudan yatırım, öteki ise fason üretimdir (Gereffi, 2005).

Bu değişikliklerin hem gelişmiş hem de gelişmekte olan ülkelerdeki toplumlar için önemli sonuçları oldu. Gelişmiş ülkelerde üretim sektöründeki işçilerin oranı önemli miktarda azaldı.' Buna karşın, hizmet sektöründeki çalışanların oranı arttı. İkinci Dünya Savaşı sonrasında Keynezyen politikalar ve cömert refah devletlerinin ortaya çıkardığı müreffeh mavi yakalı işçi sınıfı ortadan kalkmaya başladı. Sanayileşmiş ülkelerde ciddi bir işsizlik sorunu ortaya çıktı. Üretim sektöründeki işlerini kaybeden işçilerin hizmet sektöründe bulabildikleri işler çoğu zaman daha az kazandıran işler olmuştur (bu konularda yapılan çalışmaların ayrıntılı bir incelemesi için Brady vd., 2007). Buna karşın şirketlerin dünya sathına yayılan üretim ve diğer ekonomik faaliyetlerini yöneten teknik ve yönetici kitlenin gelirlerinde ve gücünde artış oldu. Bu da bu ülkelerde gelir eşitsizliğinin artmasına sebep olmuştur. Ekonomist Simon Head'e göre ABD'de 19731995 arasında en tepedeki \% 20 hariç çalışanların reel gelirleri \% 18 oranında azalmıştır. Yine ekonomist olan Krugman'in hesaplamalarına göre ise 1979-1989 yılları arasında Amerikan toplumunun en tepesindeki \% 1'in gelirleri ikiye katlanmıştır (Aktaran Sennett, 1998).

1 Bu düşüşteki tek sebep, üretimin gelişmekte olan ülkelere kayması değildir. Bunda artan makineleşme ve verimlilik de etkili olmuştur. 
Aynı dönemde gelişmekte olan ülkelerde ise emek yoğun sektörlerde önemli büyümeler olmuştur. Güney Kore, Tayvan ve Singapur gibi Uzak Asya ülkelerinden başlayarak gelişmekte olan ülkeler emek yoğun ürünlerin ihracatçısı hâline gelmişlerdir. Buna bağlı olarak bu sektörlerde çalışan çoğunluğu vasıfsız işçilerin sayısında artış olmuştur (Kaya, 2010). Bu süreçte, bahsi geçen ülkelerde mutlak fakirlik oranı düşmekle beraber fakirlik ortadan kalkmamıştır. Ekonomik küreselleşmenin tüm dünya ülkelerini içine almaya başlaması ve özellikle Hindistan ve Çin gibi ülkelerin dünyaya açıışı ile beraber gelişmekte olan ülkelerde büyük bir maliyetleri düşük tutma baskısı oluşmuş ve emek yoğun sektörlerde çalışan işçilerin fakirliği aşmalarını sağlayacak para kazanmaları neredeyse imkânsız hâle gelmiştir (Goldsmith ve Mander, 2001). Bu yüzden daha yüksek getirisi olan ekonomik faaliyetlere geçemeyen ve merkeze doğru kayamayan ülkelerde fakirlikte artışlar olmuştur.

Güney Kore ve Tayvan gibi bazı gelişmekte olan ülkeler emek yoğun sektörlerden teknoloji yoğun sektörlere geçiş yaparak ve küresel markalar oluşturarak küresel oyuncular hâline gelmişlerdir. Bu ülkelerdeki firmalar merkez ülkelerdeki firmaları takiben diğer gelişmekte olan ülkelerde yatırım yapmaya veya fason üretim yaptırmaya başlamışlardır. Bu ülkelerde özellikle yaşam standartlarında önemli artışlar olmuştur. Bu geçişi gerçekleştiremeyen Latin Amerika ülkeleri gibi ülkelerde ise yukarıda bahsettiğimiz sebeplerden dolayı yaşam standartları yerinde saymış ve hatta gerilemiştir. Fakat küresel ekonomide başarılı oyuncular hâline gelen ülkelerde bile ilk zamanlar tarıma dayalı sistemden sanayiye dayanan sisteme geçişle kısmen azalan eşitsizlik, sonraki dönemlerde artmaya başlamıştır. Kore ve Tayvan'da son yıllarda artan gelir adaletsizliği buna güzel bir örnektir (Robinson ve Haris, 2000; Sklair, 2001).

Türkiye küresel ekonomiye entegrasyonunu Güney Kore, Tayvan ve Singapur gibi ülkelerin hemen arkasından başlatmış olsa da bu ülkelerin başarılarını tam olarak tekrarlayamamıştır. Küresel iktisadi entegrasyonun otuzuncu yılında Türkiye ekonomisine hâlâ emek yoğun ve orta seviye teknolojilere dayanan sektörler hâkimdir. Uluslararası yapıya kavuşan veya küresel marka üretebilen bir Türk şirketi hâlâ yok denebilir. Son 30 yılda yaşanan büyük değişikliklere rağmen hâlâ üstesinden gelinememiş olan bu tıkanıklığın önemli toplumsal sonuçları olmuştur. Takip eden kısımda Türkiye'nin küresel entegrasyonu ve sonuçları tartışılacaktır.

\section{Türkiye'de Küreselleşme ve Küresel Ekonomiye Entegrasyon}

İkinci Dünya Savaşı sonrası Türkiye ekonomisini üç ana döneme ayırmak mümkündür. Bunlardan birincisi 1950'lerde tarım ürünlerinin ve doğal kaynakların ihracatına ve sanayi ürünlerinin ithalatına dayalı göreceli liberal dönem; ikincisi ağır sanayiye yönelen 1960 ve 1980 arası ithal ikameci, kapalı dönem ve sonuncusu ise 1980 sonrası emek yoğun sektörlerdeki ihracata dayanan küresel entegrasyon dönemidir (Boratav, 2003; 
Öniş, 2003). En başta da belirttiğimiz gibi bu çalışmada Türkiye'de küresel ekonomiye entegrasyon dönemi olan 1980 ve sonrasına yoğunlaşacağız.

1980 yılı Türk ekonomisinde çok önemli ve kökten değişikliklerin başlama dönemiydi. 1970'lerin sonlarında, siyasi kavgalarda binlerce insanın öldürüldüğü, temel tüketim maddelerinin bile piyasada bulunamadığı, her tür malda karaborsanın oluştuğu bir ortam söz konusuydu (Aydın, 2005). Devlet borçlarını ödemekte güçlük çekiyor ve enflasyon giderek artıyordu. Bu buhranın üstesinden gelmek için o dönemde hükûmet, 1980 yılının Ocak ayında tarihe 24 Ocak Kararları olarak geçecek IMF destekli bir kemer sıkma programı başlattı. Program, temel olarak dış ticareti artıırıp, yabancı yatırımları teşvik ederek ekonomide büyüme ve istikrar sağlamayı hedeflemekteydi. Program ayrıca kamu iktisadi teşekküllerinin özelleştirilmesini ve esnek bir döviz kuruna geçişi de içermekteydi.

12 Eylül 1980'de, Tük Silahlı Kuvvetleri ülkedeki siyasi ve ekonomik durumu bahane ederek yönetime el koydu. 12 Eylül rejimi genel olarak başlatılmış olan kemer sıkma programına sadık kaldı ve programın mimarlarından Turgut Özal'ı darbeden sonra kurulan geçici hükûmetin maliye bakanı olarak atadı. 1983 seçimleriyle iktidara gelen Turgut Özal hükûmeti, liberalleşmeyi ve küresel ekonomiyle entegrasyonu daha da hızlandırdı. Özal hükûmeti, bankacılık ve ticaret sistemlerini büyük oranda küresel ekonomiye açtı. Yabancı yatırımcılar üzerindeki çoğu sınırlamalar bu dönemde kaldırıldı. 1991'e kadar süren bu dönemde ekonomi önemli ölçüde büyümüş ve ithalat ve ihracatta o zamana kadar görülmeyen artışlar yaşanmışsa da yüksek enflasyon, ulusal paranın değer kaybı ve sürekli artan iç ve dış borçlar ciddi sorunlar olarak ortaya çıkmıştır.

1991 seçimleriyle Özal hükûmeti iktidardan uzaklaşmış olsa da takip eden dönemde küresel ekonomiye entegrasyon süreci bütün hızıyla devam etti. Kamu iktisadi teşekküllerinin özelleştirilmesi hızlandı (Aydın, 2005). Ulusal borç ve enflasyon ise büyümeye devam etti. 1990 'ı yıllar ve $2000^{\prime}$ lerin başı Türkiye için ekonomik ve siyasi krizlerin yaşandığı yıllar oldu. 1994 yılında çok ciddi bir ekonomik buhran yaşayan Türkiye, 1997-1998 yıllarında ordunun Erbakan hükûmetine müdahalesiyle bir siyasi istikrarsızlık dönemine de girdi. 2001 yılında ise Türkiye tarihinin en ağır iktisadi buhranlarından biri yaşandı. Bu süreçte birçok banka battı ve mali sistem neredeyse çökme noktasına geldi. Bu krizlerin ardından, Türkiye IMF ile yeni anlaşmalar imzaladı ki bu anlaşmalar ülkeyi ziyadesiyle küresel ekonomiye açılmaya itti (Aydın, 2005).

2002 yılında iktidara gelen ve devam eden AKP hükûmetleri döneminde de Türkiye küresel ekonomiye entegrasyon sürecinde ilerlemeye devam etti. Hükûmet 2001 Krizi'nden sonra IMF ile imzalanan anlaşmalara sadık kaldı ve yabancı yatırımı daha da özendiren ve yabancılara ülke sınırları içinde mülk edinme hakkı getiren düzenlemeler çıkardı. Bu dönemde devletin enerji, telekomünikasyon sektörlerdeki varlığı özelleştirmeler yoluyla büyük oranda sona erdi. Bu dönemde ayrıca ihracat ve ithalatta Özal dönemindeki sıçramaya benzeyen çok önemli artışlar yaşandı. 
Kısaca özetlediğimiz bu dönemde ekonomide yaşanan değişimleri daha iyi anlamak için yabancı yatırım girişlerine, ithalat ve ihracat rakamlarına ayrıntılı olarak bakmak faydalı olacaktır. Tablo 1, 1975-2010 yılları arasında Türkiye'nin doğrudan yabancı yatırım (DYY), ithalat ve ihracat miktarlarını göstermektedir. Tabloya baktığımızda ilk dikkatimizi çeken şey ithalat ve ihracattaki çok önemli artışlara karşın, DYY stokunda 1980-2010 arasında gayrisafi millî hasılaya (GSMH) oran açısından önemli bir artış yaşanmadığıdır. Son yıllarda bir miktar artış göstermiş olsa da doğrudan dış yatırımların Türkiye'nin küresel ekonomiye entegrasyonunda çok önemli bir rol oynamadığı ve bu entegrasyonun genelde uluslararası ticaret üzerinden gerçekleştiği görülmektedir.

\section{Tablo 1.}

Türkiye'de Doğrudan Yabancı Yatırım ve Dış Ticaret (1975-2009)

\begin{tabular}{|c|c|c|c|c|c|c|}
\hline & \multicolumn{2}{|c|}{$\begin{array}{c}\text { Doğrudan Yabancı } \\
\text { Yatırım Stoku }\end{array}$} & \multicolumn{2}{|c|}{ İhracat } & \multicolumn{2}{|c|}{ İthalat } \\
\hline & $\begin{array}{l}\text { Milyar } \\
\text { ABD \$ }\end{array}$ & $\begin{array}{l}\% \text { Gayrisafi } \\
\text { Millî Hasıla }\end{array}$ & $\begin{array}{c}\text { Milyar ABD } \\
\$\end{array}$ & $\begin{array}{l}\% \text { Gayrisafi } \\
\text { Millî Hasıla }\end{array}$ & $\begin{array}{c}\text { Milyar ABD } \\
\$\end{array}$ & $\begin{array}{l}\text { \% Gayrisafi } \\
\text { Millî Hasıla }\end{array}$ \\
\hline 1975 & $\mathrm{KY}$ & KY & 1.4 & 3,1 & 4.7 & 10,5 \\
\hline 1980 & 8.8 & 12 & 2.9 & 4,2 & 7.9 & 11,4 \\
\hline 1985 & 9.2 & 14 & 7.9 & 11,7 & 11.3 & 16,8 \\
\hline 1990 & 11.1 & 7 & 12.9 & 8,6 & 22.3 & 14,9 \\
\hline 1995 & 14.9 & 9 & 21.6 & 12,7 & 35.7 & 21,0 \\
\hline 2000 & 19.2 & 8 & 27.7 & 11,5 & 54.5 & 20,4 \\
\hline 2005 & 71.1 & 15 & 73.4 & 15,1 & 116.7 & 24,1 \\
\hline $2010^{a}$ & 77.7 & 13 & 113.8 & 18,4 & 185.4 & 30,1 \\
\hline \multicolumn{7}{|c|}{ Kaynak: Türkiye İstatistik Kurumu [TÜiK], 2010a; United Nations Conference on Trade and Development [UNCTAD], 2010; } \\
\hline
\end{tabular}

Tabloya yakından bakıldığında 1980'de Türkiye'nin GSMH'nin \% 12'sine tekabül eden bir DYY stokuna sahip olduğu görülmektedir (UNCTAD, 2010). 2009'da ise DYY stoku 77.7 milyar ABD dolarına çıkmış olsa da GSMH'ye olan oran yine \% 13 civarında kalmıştır. 1980'deki DYY stoku seviyesi 1960-1977 ithal ikame dönemi boyunca gerçekleştirilen yabancı yatırımlarına dayanmaktaydı. Bu dönem boyunca, yabancı şirketler devlet tarafından koyulan korumacı engelleri aşmak için yerli sermaye ile ortak teşebbüslere katılmışlardır (Keyder, 1987). 1990'lardaki düşüşten sonra yaşanan 2000'lerdeki artış ise daha çok enerji ve telekomünikasyon alanındaki büyük kamu iktisadi teşekküllerinin özelleştirilmesinden ve özel sektöre ait bazı büyük bankaların yabancı yatırımcılar tarafından satın alınmasından kaynaklanan ve ekonominin tümüne çok etki etmeyen bir yapıya sahiptir (Türkiye Cumhuriyet Merkez Bankası [TCMB], 2006). 
Tablo 1, Türkiye'nin toplam ihracatının 1980'de GSMH'nin \% 4,2'sine tekabül eden 2.9 milyar dolar olduğunu göstermektedir. 1985'e gelindiğinde ise ihracat GSMH'nin \% 11 'ine yani 7.9 milyar dolara fırlamıştır. Sonraki yıllarda sürekli bir artış gösteren ihracat 2000'li yıllarda yeniden bir sıçrama göstererek 2010 yılında GSMH'nin \% 18'ine denk gelen 113 milyar dolar düzeyine erişmiştir. İhracata benzer biçimde yükselen ithalat da 2010'a gelindiğinde yıllık 185 milyar ABD dolarının üstüne çıkmıştır.

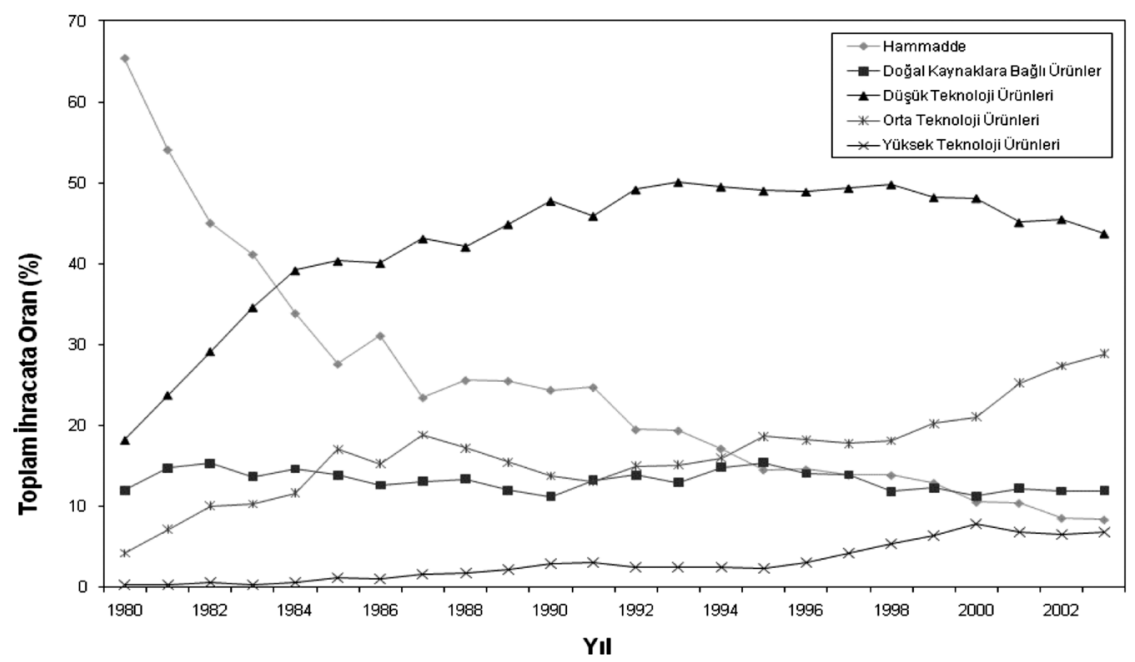

Şekil 1. Türkiye'nin Ihracatının Teknolojik Dağılımı (1980-2003)

Kaynak: Kaya (2008).

Bu dönemde Türkiye'nin ihracat yapısı da önemli ölçüde değişim geçirmiştir. Şekil 1, Türkiye'nin 1980 ve 2003 yılları arası ihracatının teknolojik dağılımını göstermektedir. 1980'de Türkiye ihracatının \% 70'e yakınını tarım ürünleri ve madenler gibi ham madde ürünleri oluşturmaktaydı. Sanayi ürünleri ihracatı \% 30'lar civarındaydı ve önemli miktarda tarım ürünlerinin işlenmesine dayanmaktaydı. 1980'de başlayan küresel ekonomiye entegrasyon süreci ile birlikte emek yoğun ve düşük teknolojili tekstil ve konfeksiyon gibi sektörlerin ihracata olan katkısı çok büyük bir sıçrama yaptı. 1980'lerin sonunda, yükselmeye devam eden Türkiye ihracatının yarısını bu tür ürünler oluşturuyordu. Bu dönemde, tarım ürünleri ve ham maddelerin ihracattaki payı sürekli azalarak 2000'lerde \% 10'un altına düştü. Türkiye küresel ekonomiye açılımla birlikte görünüşte sanayi ürünleri ihracatçısı bir ülke hâline gelmişse de Güney Kore ve Tayvan vb. ülkelerin yaptığı gibi emek yoğun sektörlerden orta ve yüksek teknoloji gerektiren sektörlere geçişi tam olarak gerçekleştirememiştir. Temel olarak düşük işçilik maliyetine dayanan sektörler Türkiye ihracatının çoğunluğunu oluşturmaya devam etmişlerdir. Yüksek teknoloji gerektiren ürünlerin ihracattaki payı son yıllarda artmışsa da hâlâ 
\% 10'un altıdadır. Bu durum özellikle Çin ve Hindistan gibi büyük ve ucuz iş gücüne sahip ülkelerin 1990'larda kapılarını uluslararası şirketlere ve küresel ekonomiye açmalarıyla beraber Türkiye ekonomisi için büyük sorunlar doğurmuştur.

Özet olarak, Türkiye 1980 'de başlayarak küresel ekonomiye temel olarak uluslararası ticarete dayanan hızlı bir entegrasyon yaşamıştır. Bu entegrasyon siyasi çalkantılara ve ekonomik krizlere rağmen hızlanarak devam etmiş, Türkiye toplumunu ve devleti büyük oranda değiştirmiştir. Takip eden kısımlarda küresel ekonomiye entegrasyon sürecinin Türkiye'nin; devletin yapısına ve gücüne, çalışma hayatına, toplumsal refah ve eşitsizliğe olan etkileri ayrı ayrı tartışılacaktır.

\section{Küreselleşme, Devlet ve Kurumsal Yapı}

Türkiye'de her zaman temeli Osmanlı geçmişine de dayanan güçlü bir devlet yapısı olagelmiştir. Türkiye Cumhuriyeti, güçlü bir merkeziyetçi yapıya sahip olan Osmanlı İmparatorluğu bürokrasisi içinden gelen yöneticiler tarafından kurulmuştur. Yeni kurulan Cumhuriyet son dönem Osmanlı bürokrasini de çoğunlukla kendi hizmetine almıştır. Türkiye 1950 yılından itibaren demokratik sisteme geçmişse de bürokrasi, özellikle de askerî bürokrasi etkinliğini korumaya devam etmiştir. Bunu 1950-1998 yılları arasında gerçekleşen dört askerî müdahale de açık bir biçimde ortaya koymaktadır. Hatta bürokrasinin bu güçlü rolü Türk akademisyenlerini devlet çalışanlarını ayrı bir toplumsal sınıf olarak tanımlamaya itmiştir (örnek Keyder, 1987; Mardin, 1994). Bazı entelektüel ve akademisyenler sermayenin geri plandaki gücünü öne süren açıklamalar yapmaya çalışmışsalar da (örneğin Boratav, 2003, 2004, 2005; Öncü, 2003), sermayeden bağımsız ve güçlü bir yapı olarak bürokrasi, Türk aydınlarının ve akademisyenlerinin Türkiye algısında yerini hep koruyagelmiştir.

Fakat çalışmamıza konu olan 1980-2010 arası dönem Türkiye'nin devlet yapısı ve bürokrasinin konumunda da çok önemli değişikliklere yol açmıştır. Bu dönem boyunca devletin ve bürokrasinin ekonomideki varlığı ve kontrolü sürekli artan bir biçimde azalmıştır. Bu süreçte IMF gibi uluslararası kurumların etkisi çok büyük olmuştur. Türkiye 1980'den sonra IMF ile 24 Ocak Kararları ile başlayan birçok anlaşma imzalamıştır. Özellikle ekonomik krizler sonrası devletin ve bürokrasinin güçsüzlüğünü iyi değerlendiren IMF, dış destek ve kredi için ekonomik liberalleşmenin yanında hep devletin ekonomideki varlığının ve kontrolünün azaltılmasını koşul olarak öne sürmüştür. Bu bağlamda, 1980'lerin başından itibaren hükûmetler sanayi, bankacılık, hizmet ve madencilik gibi alanlarda kamu iktisadi teşekkülleri olarak da bilinen devlete ait işletmeleri ve kurumları özelleştirmeye girişmişlerdir.

Küreselleşme ile beraber devletin özellikle ekonomideki kurumsal yapısı da önemli ölçüde değişikliğe uğramıştır. 1980'e kadar ekonomi ve kalkınma politikalarının belirlenmesinde önemli rol oynanan Devlet Planlama Teşkilatının (DPT) gücü azalırken Hazine ve özellikle de süreç içinde özerk bir yapıya kavuşan Merkez Bankası güçlen- 
miştir (Boratav, 2003). Buna ek olarak toplumsal yapı içinde bürokratlar saygınlık ve zenginlik açısından yeni gelişen girişimci ve profesyonel sınıf tarafından gölgelenmiştir. Toplumsal sınıfı yapısı içinde de küresel ekonomi ile bağlantılı girişimci ve profesyonel sınıflar 1980 sonrası katlanarak büyürken, devlet memurlarının sayısındaki artış ve bürokrasideki genişleme göreceli olarak daha sınırlı olmuştur (Kaya, 2008).

Bütün bunlara bakarak devletin 1980 öncesi ekonomideki yaygın ve doğrudan varlığının küresel iktisadi entegrasyonla birlikte yerini daha sınırlı ve daha çok düzenleyici bir role bıraktığını söylemek mümkündür. Küreselleşme ile birlikte diğer ülkelerde de görülen bu durumu O’Riain (2000) "kurumsal tamponların" kaybı olarak adlandırmaktadır. Wade (2005) ise "kalkınma alanının" yok oluşu tabirini kullanmaktadır. Özet olarak bugün baktığımızda Türkiye'de devlet hâlâ hatırı sayılır bir güce ve bürokratik yapıya sahip olsa da devletin ekonomik ve sosyal alanda yapabileceklerinin Dünya Ticaret Örgütü (WTO) ve IMF gibi uluslararası kurumlar ve bağlı olduğu antlaşmalar tarafından önemli derecede sınırlandırıldığını görmekteyiz.

\section{Küreselleşme, İşçiler ve Çalışma Hayatı}

Küresel ekonomiye entegrasyon Türkiye'deki çalışma hayatına çok büyük etkiler yapmıştır. Tablo 2'de görüldüğü gibi 1980 yılında Türkiye'de çalışan nüfusun yarıdan fazlası tarımda istihdam edilmiş durumdaydı. Sanayinin istihdamdaki oranı \% 20 civarındaydı. Tarımdaki istihdam 1980'den sonraki dönemde sürekli azalmış 2010 yılına gelindiğinde toplam çalışan nüfusun \% 25'ine kadar gerilemiştir. Çalışan erkeklerin arasındaki oran ise \% 20'nin altına gerilemiştir (World Bank, 2010).

Aynı dönemde sanayideki istihdam hatırı sayılır bir artışla 2010 yılında \% 26'lara yükselmiştir. Fakat sanayide çalışan iş gücü için asıl değişim kendi iç yapısında gerçekleşmiştir. 1980 öncesi sanayideki istihdam daha çok ithal ikameci sistem içinde büyüyen ve genelde iç piyasa için üretim yapan özel sermayeye ait orta ve büyük ölçekli firmalarla, daha çok büyük ölçekte olan kamu iktisadi teşekküllerinde gerçekleşmekteydi. Sanayide çalışan işçilerin büyük kısmı da güçlü ve yaygın sendikalar tarafından örgütlenmiş hâldeydi.

\section{Tablo 2.}

Türkiye'de Istihdamın Tarım, Sanayi ve Hizmet Sektörleri Arasındaki Dağılımı (1980-2008) (\%)

\begin{tabular}{lcccc}
\hline & Tarım & Sanayi & Hizmet & Toplam \\
\hline $\mathbf{1 9 8 0}$ & 53,6 & 20,5 & 25,9 & 100 \\
\hline $\mathbf{1 9 8 8}$ & 47,1 & 21 & 31,9 & 100 \\
\hline $\mathbf{1 9 9 0}$ & 47 & 20 & 33 & 100 \\
\hline $\mathbf{1 9 9 5}$ & 44 & 22 & 34 & 100 \\
\hline $\mathbf{2 0 0 0}$ & 36 & 24 & 40 & 100 \\
\hline $\mathbf{2 0 0 5}$ & 29,5 & 24,8 & 45,7 & 100 \\
\hline $\mathbf{2 0 1 0}$ & 25,1 & 26,2 & 48,7 & 100 \\
\hline Kaynak: Türkiye Istatistik Kurumu [TÜiK], 2010b; World Bank, 2010.
\end{tabular}


1980'den sonraki dönemde kamu iktisadi teşekküllerinin özelleştirilmesi ve küresel ekonomiyle rekabette zorluk çeken büyük yerli firmaların yerini daha çok küçük ölçekli ihracata dayanan firmaların almasıyla sanayideki istihdamın yapısı hızla değişti. Vasıflı ve örgütlü işçi sınıfının yerini büyük ölçüde vasıfsız ve sendikalara bağlı olamayan, birçoğu kayıt dışı olarak çalışan işçiler aldı.

Küreselleşme sürecinde devlet, iş̧̧i örgütlerine ve sendikalaşmaya olumsuz bir yaklaşım sergilemiştir. Daha sürecin başında, 12 Eylül rejimi işçi organizasyonlarını ya yasaklamış ya da güçlerini büyük ölçüde sınırlandırmıştır. Çoğu aktif üye ya hapse atılmış ya da ülkeyi terk etmiştir. Askerî yönetim, işçi hareketlerini ulusal güvenliğe ve ekonomiye zararlı unsur olarak görmüştür. Darbenin lideri olan Kenan Evren ilk konuşmasında işçilerin militanlığından ve ekonomideki yüksek ücretlerden şikâyetçi olduğunu dile getiriyordu (Boratav, 2003). Daha sonraki yıllarda sendikalar ve işçi örgütlenmesinin önü büyük ölçüde açıldıysa da 1980 öncesi güçlerini bir daha hiç yakalayamamışlardır.

Küreselleşme sürecinde sanayideki istihdamda belirli bir artış yaşanmışsa da bu kırdan kente göçen kitlelere yeterli sayıda iş sağlayabilecek bir düzeye hiçbir zaman ulaşmamıştır. Kırdan kentlere göç eden vasıfsız iş gücünün bir kısmı ihracata dayalı sektörler tarafından istihdam edilmiş, önemli bir oranı da genellikle kayıt dışı olarak hizmet sektöründe istihdam edilmişlerdir. Benzer durumlar küreselleşme ile birlikte diğer gelişmekte olan ülkelerde de yaşanmıştır (Kaya, 2008; Koo, 1990). Gelişmiş ülkelerde yurt dışına kayan imalat sektöründe işlerini kaybeden işçiler giderek genişleyen ve istihdamın \% 75-80'ini sağlamaya başlayan hizmet sektörü tarafından istihdam edilmişlerdir (Brady ve Denniston, 2006).

Hizmet sektöründeki şişmenin yanı sıra işsizlik oranı 1980-2010 yılları arasında yüksek oranda kalmıştır. Ekonomik kriz dönemlerinde \% 16-17'lere kadar çıkan işsizlik oranı genel olarak \% 10'larda seyretmiş̧ir (International Labor Organization [ILO], 2010; TÜIK, 2010b). İşsizlik oranı vasıfsız ve genç iş gücü içinde ise \% $20^{\prime}$ ler civarında seyretmiştir (TÜiK, 2010b). Bu da göstermektedir ki, küresel ekonomiye entegrasyon sürecinde Türkiye'de hızla büyüyen ihracat sektörü vasıfsız, çoğunluğu genç ve yeni şehirli kitlelere iş olanakları sağlamışsa da bu kitlelerin tamamına iş sağlayacak düzeye hiçbir zaman ulaşamamıştır.

\section{Küreselleşme, Toplumsal Refah ve Eşitsizlik}

Sosyal bilimlerde ve dünya kamuoyunda küreselleşme ile ilgili en önemli tartışmalardan biri küreselleşmenin özellikle gelişmekte olan ülkelerde fakirlik ve toplumsal eşitsizliğe etkisi üzerinedir. Tartışmanın bir tarafı küreselleşmenin gelişmekte ülkelerde tarımı terk eden nüfusa iş imkânları açarak, ülkelere ihracat ve dış yatırım yoluyla sermaye birikimi ve girişi sağlayarak toplumsal refahı olumlu etkilediğini iddia etmektedir (örneğin Bhagwati, 2004; Bhalla, 2002; Friedman, 2006). Buna karşı çıkan bazı akade- 
misyen ve küreselleşme karşıtı aktivistler ise küreselleşmenin gelişmekte olan ülkelerdeki işçilerin çok kötü şartlar altında ve çok düşük ücretlerle çalıştırıldığı, ülke kaynakIarının talan edildiği ve doğal çevrenin kirletildiği bir ortama yol açtığını söylemişlerdir. Bunlardan bazıları daha adil bir küreselleşme çağrısında bulunurken bazıları da sürecin hepten geri döndürülerek yeni bir yerelleşme dönemi önermişlerdir (FernandezKelley, 1983; Goldsmith ve Mander, 2001; Lee, 1998).

Türkiye'ye baktığımızda ise 1980-2010 küresel ekonomiye entegrasyon döneminde Türkiye'de Dünya Bankasının mutlak fakirlik göstergesi olarak kullandığı günlük 1.25 ABD dolarının altında geliri olan insan oranının 1985-2009 yılları arasında yine Dünya Bankasının kendi tahminlerine göre pek değişmediğini görmekteyiz (World Bank, 2010). ${ }^{2}$ Tablo 3'te görülebileceği gibi Türkiye'nin resmî verilerine göre ise fakirlik oranı 1990'larda \% 30'lara yakınken 2000'lerde \% 20'nin altına gerilemiştir. Bu durum son yıllarda ciddi bir iyileşme gösterse de 1980'ler ve 1990'lardaki fakirlik istatistikleri çok da sağlıklı olmadığı için bir karşılaştırma yapmayı zorlaştırmaktadır. ${ }^{3}$

Tablo 3.

Türkiye'de Fakirlik ve Gelir Dağılımı, 1985-2009.

\begin{tabular}{lcccc}
\hline & $\mathbf{1 9 8 5}$ & $\mathbf{1 9 9 5}$ & $\mathbf{2 0 0 0}$ & $\mathbf{2 0 0 9}$ \\
\hline Günlük 1.25 \$ Altında Yaşayan (\%) & 2 & 2,1 & 2 & 2 \\
\hline Fakirlik (\%) & KY & 28,3 & 27 & 18 \\
\hline Gini İndeksi & 43,6 & 41,5 & 42,7 & 41,5 \\
\hline En tepedeki \% 10'un Millî Gelirden Aldığı Pay & 35,3 & 32,3 & 33,5 & 32,1 \\
\hline En tepedeki \% 20'nin Millî Gelirden Aldığı Pay & 50 & 47,7 & 48,8 & 47,6 \\
\hline En alttaki \% 10'un Millî Gelirden Aldığı Pay & 2,37 & 2,27 & 2,21 & 2,07 \\
\hline $\begin{array}{l}\text { En alttaki \% 20'nin Millî Gelirden Aldığı Pay } \\
\text { Kaynak: Türkiye İstatistik Kurumu [Tüik], 2010c; World Bank, 2010. }\end{array}$ & 5,91 & 5,8 & 5,64 & 5,57 \\
KY: Kayıt Yok & & & & \\
\hline
\end{tabular}

Aynı dönemde ise Türkiye'de gelir adaletsizliği göstergelerinde önemli bir değişiklik olmamıştır. Tablo 3'e bakınca hem akademi hem de devletler tarafından en yaygın biçimde kullanılan gelir adaletsizliği göstergesi olan Gini indeksi rakamlarının ve en tepedeki \% 10 ve \% 20 nüfusun millî gelirden aldıkları payın ise az miktarda azaldığını görmekteyiz. Buna karşın en alttaki \% 10 ve 20 nüfusun millî gelirden aldığı payın da bir miktar azaldığını gözlemliyoruz. Sosyal bilimlerde gelir adalersizligini ölçmek üzere

2 TÜIK tarafından yapılan hesaplamalara göre ise günlük 1.25 ABD dolarının altında yaşayan fert oranı yok denecek kadar azdır (TÜiK, 2010c).

3 Türkiye'de dört kişilik bir hane için 2010 yılında açlık sınırı aylık 318 YTL, yoksulluk sınırı ise aylık 896 YTL olarak belirlenmiştir (TÜiK, 2010c). 
en yaygın biçimde kullanılan yöntemlerden olan ğını indeksi de bo dönemde iniş çıkışlar yaşamakla beraber genelde aynı düzeyde seyretmiştir.

1980 ve 2010 yılları arasında Türkiye'nin sınıfsal yapısı üzerinde yapılan analizler ise bu dönemde en tepedeki girişimci ve profesyonel sınıflarla en altta hizmet ve imalat sektörlerinde çalışan vasıfsız işçilerden oluşan proleter sınıfın genişlediğini göstermiştir (Boratav, 2004, 2005; Kaya, 2008). Sonuç olarak denilebilir ki küresel ekonomiye entegrasyon süreci Türkiye'de toplumsal refah ve eşitsizliği artırıcı büyük bir olumsuz etkide bulunmamışsa da sürecin mimarları olan IMF ve Dünya Bankası gibi kuruluşlar tarafından iddia edildiği gibi toplumsal refahı artıran ve ekonomik büyümeden gelen kazanımları tabana yayan bir etkide de bulunmamıştır.

\section{Sonuç}

Küresel ekonomiye kapılarını açtığından beri geçen otuz yılda Türkiye'de çok şey değişti. İç piyasaya yönelik olarak çalışan ve devlet tarafından korunan özel sektörün yetmediği alanlarda devletin doğrudan kendisinin yer aldığı ekonomik yapı, yerini ihracata yönelik, küçük ve orta büyüklükte işletmelerin rolünün büyük oranda arttığı, devletin doğrudan varlığının olmadığı bir sisteme bıraktı. Türkiye, çalışan nüfusunun yarısından fazlasının tarımda istihdam edildiği bir yapıdan, hizmet sektörü ve sanayinin en büyük işverenler hâline geldiği bir yapıya evrildi. 1980'de ithalatı ve ihracatı nerdeyse yok denecek kadar az olan Türkiye, 2010'a gelindiğine uluslararası ticaret ağlarının önemli üyelerinden biri hâline gelmiştir. Fakat tüm bu değişimlere rağmen Türkiye, Güney Kore ve Tayvan gibi ülkelerin başarılarını tam olarak tekrarlayamamıştır. Bugün Türkiye hâlâ küresel ekonomide ucuz iş gücüne dayanarak kendine bir yer edinmeye çalışmaktadır. Bu açıdan Türkiye'nin tecrübesi küreselleşme sürecinde benzer sıkıntıları yaşayan Latin Amerika, Orta Doğu ve Doğu Avrupa ülkelerine ışık tutacak düzeydedir.

Küreselleşme sürecinde Türkiye'nin devlet ve toplumsal yapısında önemli değişiklikler yaşanmıştır. Son otuz yılda devletin ekonomideki doğrudan varlığı nerdeyse tamamen ortadan kalkmış ve bürokrasinin iktisadi politikalar üzerindeki etkisi önemli ölçüde azalmıştır. Toplumsal yapı içinde bürokratlar saygınlık ve zenginlik açısından küreselleşme sürecinde katlanarak büyüyen girişimci ve profesyonel sınıflar tarafından gölgelenir hâle gelmiştir.

Küreselleşme süreci içinde büyüyen ekonomi ise toplumun geneline yayılan bir refah getirememiştir. Yaşanan ekonomik büyümeye, ithalat ve ihracattaki patlamaya ve hatırı sayılır dış sermaye girişine rağmen fakirlik, işsizlik ve gelir adaletsizliği konularında önemli bir iyileşme sağlanamamıştır. işsizlik oranı kriz dönemlerindeki çok yüksek oranlardan aşağı çekilebilmişse de \% 10'ların altına hiç inmemiştir. Gelir ve zen- 
ginlik açısından toplumun en tepesindeki \% 10 ve 20'nin millî gelirden aldığı pay bu dönem boyunca hep yüksek kalmıştır. Bazı iyileşmeler sağlanmakla beraber, fakirlik oranı da önemli ölçüde gerilememiştir. Bu dönemde en kazançlı çıkan kesim ise küresel ekonomiye iş yapan veya küresel ekonomiyle bağlantıyı yürüten girişimci ve profesyonel sınıflar ve gruplar olmuştur. Başta İstanbul olmak üzere küresel ekonomiyle bağlantılı az sayıda kentte yoğunlaşan bu kitleleler ile toplumun gerisi arasındaki uçurum artmıştır.

Bu sebeple, önümüzdeki yıllarda sosyal politikalar geliştirilirken, IMF gibi küreselleşmenin bayraktarlığını ve jandarmalığını yapan uluslararası kuruluşların tahminlerinin aksine, Türkiye'de küresel ekonomiye entegrasyon sürecinde yaşanan ekonomik büyümenin tek başına toplumsal refahı sağlayamadığının ve yükselen suların herkesin teknesini yükseltmediğinin farkında olunmalıdır.

\section{Kaynakça}

Aydın, Z. (2005). The political economy of Turkey. Ann Arbor, MI: Pluto Press.

Bairoch, P. (1996). Globalisation myths and realities: One century of external trade and foreign investment. In R. Boyer \& D. Drache (Eds.), States against markets (pp. 173-192). New York, NY: Routledge.

Baldwin, R. E. \& Martin, P. (1999). Two waves of globalization: Superficial similarities, fundamental differences. In H. Siebert (Ed.), Globalization and Labor (pp. 3-58). Germany: Institutut fur Welwirtschaft an der Univesitat Kiel.

Bhagwati, J. (2004). In defense of globalization. New York, NY: Oxford University Press.

Bhalla, S. S. (2002). Imagine there's no country: Poverty, Inequality, and growth in the era of globalization. Washington, DC: Peterson Institute.

Boratav, K. (2003). Türkiye iktisat tarihi: 1908-2002. Ankara: İmge.

Boratav, K. (2004). Istanbul ve Anadolu'dan sınıf profilleri. Ankara: Imge.

Boratav, K. (2005). 1980'li yıllarda Türkiye'de sosyal sınıflar ve bölüşüm. Ankara: İmge.

Brady, D. \& Denniston, R. (2006). Economic globalization, industrialization and deindustrialization in affluent democracies, 1960-2001. Social Forces, 85, 297-329.

Brady, D., Beckfield, J., \& Zhao, W. (2007). The consequences of economic globalization for affluent democracies. Annual Review of Sociology, 33, 313-334.

Castells, M. (1996). The information age. Cambridge, MA: Blackwell.

Chase-Dunn, C., Kawano, Y., \& Brewer, B. D. (2000). Trade Globalization since 1795: Waves of Integration in the World-System. American Sociological Review, 65(1), 77-95.

Dicken, P. (2003). Global shift: Reshaping the global economic map in the $21^{\text {st }}$ century (4th edt.). New York, NY: Guilford Press.

Fernandez-Kelley, P. (1983). For we are sold, I and my people. Albany, NY: SUNY Press.

Friedman, T. (1999). The lexus and the olive tree: Understanding globalization. New York, NY: Farrar, Straus \& Giroux.

Friedman, T. (2006). The world is flat: A short history of the twenty-first century. New York, NY: Farrar, Straus and Giroux.

Fröbel, F., Heinrichs, J., \& Kreye, O. (1980). The new international division of Labor. Cambridge, UK: Cambridge University Press. 
Gereffi, G. (2005). The international economy and economic development. In N. J. Smelser \& R. Swedberg (Eds.), The handbook of economic sociology (pp. 160-182). Princeton, NJ: Princeton University Press.

Goldsmith, E. \& Mander, J. (2001). The case against the global economy: And for a turn towards localization. San Francisco, CA: Earthscan Publications.

Greider, W. (1997). One world, ready or not: The manic logic of global capitalism. New York, NY: Simon\&Schuster.

Guillen, M. F. (2001). Is globalization civilizing, destructive or feeble? A critique of five key debates in the social science literature. Annual Review of Sociology, 27, 235-260.

Held, D., McGrew, A. G., Goldblatt, D, \& Perraton, J. (1999). Global transformations. Stanford, CA: Stanford University Press.

Hirst, P. \& Thompson, G. (1996). Globalization in question. Cambridge, MA: Polity Press.

Hoogvelt, A. (1997). Globalization and the postcolonial world. Baltimore, MD: The Johns Hopkins University Press.

International Labor Organization. (2010). Yearly data of total and economically active population, employment, unemployment, hours of work, wages, Labor cost, consumer price indices, occupational injuries, strikes and lockouts: 1969-2008. Retrieved on September 22, 2010, from http://laborsta.ilo.org/STP/guest.

Kaya, Y. (2008). Proletarianization with polarization: Industrialization, globalization and social class in Turkey, 1980-2005. Research in Social Stratification and Mobility, 26(2), 161-181.

Kaya, Y. (2010). Globalization and industrialization in 64 developing countries, 1980-2003. Social Forces, 88(3), 1153-1182.

Keyder, Ç. (1987). State and class in Turkey: A study in capitalist development. New York, NY: Verso.

Koo, H. (1990). From farm to factory: Proletarianization in Korea. American Sociological Review, 55, 669681.

Lee, C. K. (1998). Gender and the South China Miracle. Berkely, CA: University of California Press.

Mardin, Ş. (1994). Türk modernleşmesi. İstanbul: iletişim Yayınları.

McMichael, P. (2000). Development and social change: A global perspective. Thosand Oaks, CA: Pine Forge Press.

McMichael, P. (2001). World systems analysis, globalization and incorporated comparison. Journal of the World-systems Research, 3, 668-690.

Ohmae, K. (1995). The end of the nation state: The rise of regional economies. New York, NY: The Free Press Ohmae, K. (1999). The borderless world: Power and strategy in the Interlinked economy. New York, NY: HarperCollins Publishers.

O'Riain, S. (2000). States and markets in an Era of globalization. Annual Review of Sociology, 26, 187-213.

Obstfeld, M. \& Taylor, A. M. (2003). Globalization and capital markets. In M.D. Bordo, A. M. Taylor \& J. G. Williamson (Eds.), Globalization in historical perspective (pp. 121-188). Chicago, IL: The University of Chicago Press.

Öncü, A. (2003). Dictatorship plus hegemony: A gramscian analysis of the Turkish state. Science and Society, 67, 303-328.

Öniş, Ziya. (2003). Post-war economic development performance of Turkish economy: A political economy perspective. In C. Kollias \& G. Günlük-Şenesen (Eds.), Greece and Turkey in the $21^{\text {st }}$ century: Conflict or cooperation (pp. 67-97) New York, NY: Nova Science Publishers.

Robertson, R. (1992). Globalization: Social theory and global culture. London, UK: Sage Publications.

Robinson, W. I. \& Haris, J. (2000). Towards a global ruling class? Globalization and the transnational capitalist class. Science and Society, 64, 11-54.

Sennett, R. (1998). The corrosion of character: The personal consequences of work in the new capitalism. New York, NY: W.W. Norton \& Company Ltd.

Sklair, L. (2001). The transnational capitalist class. Oxford: Blackwell Publishers. 
Therborn, G. (2000). Globalizations: Dimensions, historical waves, regional effects, normative governance. International Sociology, 15(2), 151-179.

Türkiye Cumhuriyet Merkez Bankası. (2006). Turkish balance of payments statistics. Ankara: Türkiye Cumhuriyet Merkez Bankası.

Türkiye İstatistik Kurumu. (2010a). Dış ticaret istatistikleri. http://www.tuik.gov.tr/PreTablo.do?tb_ $\mathrm{id}=12$ \&ust_id=4 adresinden 12 Kasım 2010 tarihinde edinilmiştir.

Türkiye İstatistik Kurumu. (2010b). İsgücü istatistikleri. http://www.tuik.gov.tr/PreTablo.do?tb_ id=25\&ust_id=8 adresinden 28 Ekim 2010 tarihinde edinilmiştir.

Türkiye İstatistik Kurumu. (2010c). Gelir, tüketici, tüketim ve yoksulluk istatistikleri. http://www.tuik.gov.tr/ AltKategori.do?ust_id=7 adresinden 28 Ekim 2010 tarihinde edinilmiştir.

United Nations Conference on Trade and Development. (2010). FDI online. http://unctadstat.unctad. org/ReportFolders/reportFolders.aspx?sCS_referer=\&sCS_ChosenLang=en adresinden 12 Kasım 2010 tarihinde edinilmiştir.

Wade, R. (2005). What strategies are viable for developing countries today? The world trade organization and the shrinking of "development space". In K. P. Gallagher (Ed.), Putting development first: The importance of policy space in the WTO and IFIs (pp. 80-101). London, UK: Zed Books.

Wallerstein, I. (1974). The modern world-system, vol. 1: Capitalist agriculture and the origin of the European world-economy in the sixteenth century. New York, NY: Academic Press.

Wallerstein, I. (1980). 1980. The modern world-system, vol. II: Mercantilism and the consolidation of the European world-economy, 1600-1750. New York, NY: Academic Press.

Wallerstein, I. (1989). The modern world-system, vol. III: The second era of great expansion of the capitalist world-economy, 1730-1840s. New York, NY: Academic Press.

Wallerstein, I. (2000). Globalization or the age of transition? A long-term view of the trajectory of the world-system. International Sociology, 15(2), 249-265.

World Bank. (2010). World development indicators online. Retrieved on October 22, 2010, from http:// databank.worldbank.org/ddp/home.do?Step $=12 \& \mathrm{id}=4 \& \mathrm{CNO}=2$. 


\title{
Turkey in the Period of Globalization and Economic Integration: 2000 and Beyond
}

\author{
Yunus Kaya*
}

Keywords: Turkey, Globalization, Labor, Poverty, Inequality, Bureaucracy.

This paper analyzes the process of globalization and its impact on labor, state, social inequality and poverty in Turkey. Turkey was established in 1923, much earlier than most developing countries gained their independence. Since then, Turkey experimented with different industrialization strategies, in different historical contexts, ranging from direct entrepreneurship by the state to import-substitution industrialization based on private capital. Turkey was also among the first at being opened to the global economy by restructuring its economy in 1980, following the of East Asian countries. Within the years of opening up to the global economy Turkey became a significant exporter of, mostly low-technology, but also increasingly medium and high technology, manufactured goods. Since 1980, Turkey's exports have increased continuously, both in monetary terms and relative to GDP. Turkey has also attracted significant amount of foreign capital throughout this period. All these recent changes and its historical experience make Turkey a rich case to investigate the effect of the recent wave of economic globalization on labor, state and the well-being of the people.

Although there are significant disagreements in the literature regarding the origins and effects of globalization, it emerged as a powerful force causing social, economic, and institutional change. Since 1980, when Turkey has been opened to the global economy, the Turkish social structure has changed significantly. Turkey is no longer an agrarian society. In 2010, less than 25 percent of all working people were employed in agriculture. Among men, this rate further declines to around 19 percent. Employment in the industrial sector has increased to above 25 percent, while service sector jobs became the dominant form of employment. However, even though Turkey was able to transform itself into an export-oriented economy, it has not been able to repeat the success of some East Asian countries in growth and industrialization or technologybased development such as South Korea and Taiwan. After thirty years of globalization, Turkey is still an exporter of low and medium technology products to a larger extend. The failure to upgrade the economy revealed itself in several economic crises the country suffered within the last thirty years, especially in the 1990s. Although there were some positive developments in recent years, Turkey still has a long way to go before becoming a success story itself. As a result of this stagnation and frequent economic crises, the unemployment in Turkey remained high throughout the globa-

* Dr., University of North Carolina Wilmington. 
lization process. It never declined below 10 percent, while it rose to nearly 20 percent during the times of economic crises.

In addition, poverty and social inequality remained high in this period. According to the estimations of the World Bank, people living in absolute poverty, living with fewer than 1.25 dollars a day, remained around two percent of the society throughout this period. The calculations by the Turkish Statistical Office (TÜiK) that in recent years there has been a significant reduction in both absolute and relative poverty, but even with their calculations nearly 20 percent of the society are living under the poverty line (based on income) set by the government. In terms of income inequality, the GINI value was 43,6 in 1980. This value declined modestly to 41.5 in 2009. During the same period, the income share of lowest and top 10 and 20 percents of the society remained steady. Overall, the period of globalization in Turkey did not futher expanded inequality and poverty in the country as some in the literature would expect, but it also did not have the positive impact that was predicted by the international institutions such as the World Bank and the IMF.

Another significant change in Turkey was the decline in the relative importance and the power of the top bureaucratic elites in this period. Turkey has a long history of strong and centralized governance. Although Turkey has been governed by democratically elected governments since 1950, the bureaucracy, especially the military bureaucracy, maintained a certain level of autonomy. The era of globalization brought significant changes to the Turkish state. The presence of the state in the economy declined continuously through privatization and deregulation. The institutional structure has also changed with globalization. The State Planning Organization, which devised the plans for the import-substitution industrialization of the 1960s and 1970s, are now shadowed by the increasing role of the Treasury and the Central Bank, which gained autonomy during the globalization period. In addition to the loss of autonomy and power, with globalization, the top bureaucracy has been increasingly shadowed by the expanding professional and managerial classes in terms of its relative size but also in terms of power and reputation in the society.

To sum up, globalization transformed the economy, state, and the social structure in Turkey significantly in the last thirty years. Turkish economy is now well-integrated to the global economy. The Turkish state has a much smaller role in the economy. Most of the labor force is now employed in the service sector and the industry. However, in terms of the well-being, the gains from the globalization of the economy have been mostly limited to the managerial and professional social classes who expanded in size and increased their influence in this period. The gains for the rest of the society have been limited; if it existed at all. The case of Turkey can shed light to the problems faced by other developing countries that opened their doors to the global economy later than Turkey and who also hope to repeat the coveted East Asian success stories. The impact of the globalization on the masses has been different from what is promised by the institutions of the Washington Consensus; and the rising tides did not lift all boats, at least in the Turkish case. 